\title{
WORK OF ARTS
}

\section{Rural Migrant Workers in Independent Films}

Representations of Everyday Agency

\section{Eric FLORENCE}

The recent wave of evictions of tens of thousands of rural migrants in Beijing has served as a harsh reminder of the subaltern condition of many of these people in today's China. This essay examines how rural migrant workers have been represented in Chinese independent

documentary films. It points to the importance of conceptually linking the political economy, sociology, and cultural politics of labour in order to apprehend the subject-making processes of migrant workers in today's

China. 
It's like guerrilla warfare. What matters is to get water. Everything is demolished around

here, there is no water... Once the migrants school is demolished, you'll have nowhere to go to. How do you think that makes me feel?

I can only blame myself for not giving you

a better life.

When the Bough Breaks, Ji Dan (2010)

- he recent demolition of entire areas in the suburbs of Beijing and the ensuing wave of evictions of tens of thousands of rural migrants have served as harsh reminders of the subaltern condition of many of these people in China today. Several contributions in this volume focus on the ongoing debate on precariousness in contemporary China, shedding light on the complex changes affecting labour regimes and the increasingly diverse and fragmented labour landscapes across the country. In this essay, I will delve into a different but related issue: how rural migrant workers have been represented through a specific form of interventionChinese independent documentary films. The importance of looking at the ways various categories of rural migrants are represented, and how migrants themselves take part in their own self-representation-the so-called cultural politics of labour-hinges upon the assumption that both the study of the political economy and sociology of labour on the one hand, and the study of the cultural politics of labour on the other, are needed to apprehend the subjectmaking processes of migrant workers in today's China (Sun 2014).

Although the relationship between rural migrants and filmmakers is an unbalanced one, an exploration of independent documentary 
films provides a glimpse into how migrants' desires, aspirations, hopes for a better life, and their quest for social mobility, engage with-and are strongly shaped by-historically produced institutional and structural forces. Rural-to-urban migration processes in postMao China are deeply rooted in large-scale structural inequality of power and access to wealth. They have also been shaped by politico-institutional configurations, and by the relationship between Party-state, market forces, and capital. Hence, we can consider rural migrants in post-socialist China as standing within historically, culturally, and institutionally constituted 'matrixes' of power (Ortner 2006), i.e. the rural-urban chasm, the reformed institutions and mechanisms of demographic control and appropriation of labour, and a whole network of multi-layered hegemonic discourses.

In the late 1980s and first half of the 1990s, many of the mainstream media accounts shared an overall homogenising depiction of rural workers. Starting from the second half of the 1990s, in parallel with similar processes taking place in the fields of Chinese social sciences, media, and popular literature, some documentaries began to deconstruct the image of voiceless hordes of unsightly people 'pouring blindly' into Chinese cities (Florence 2006). Since the late 1990s, the channels of mediation of migrant workers' lives and toil in the cities have become increasingly diversified, including through popular literature, radio, TV shows, photography, and films. With digital advancements over the past decade or so, online forms of representation by both workers themselves-what Jack Qiu has defined as 'worker-generated content' (Qiu 2009)-and by urban elites, such as journalists or NGO activists, have become increasingly widespread. The categories of migrants covered by this specific form of cultural politics have also become more varied, with the inclusion of not only young factory workers, but also miners, domestic workers, vagrants, etc.

\section{A Bottom-up View}

Independent documentary films such as such as Li Hong's Return to Phoenix Bridge (1997), Wu Wengugang's Life on the 'Jianghu' (1999), Du Haibin's Along the Railway (2001), Ying Ning's Railroad of Hope (2002), Ai Xiaoming's The Train to My Hometown (2008), Fan Lixin's Last Train Home (2010), Ji Dan's When the Bough Breaks (2010), Guo Zongfu's Coal Miner (2012), Huang Weikai's Drifting (2005), Zhao Dayong's Nanjing Lu (2010), and Xu Tong's Wheat Harvest (2012) depart from the more mainstream-often paternalistic and at times voyeuristic-cinematic representations of rural migrants (Sun 2014). With their uninterrupted long sequence-shots, they provide the subjects with enough time to narrate their experiences in full. While each of these films possesses its own specificity in terms of form and cinematic arrangements, they share a bottomup perspective, often focussing on ordinary people from all walks of life who narrate their experiences and reflect on their lives, as well as on society as a whole. For such filmmakers, building a relationship of confidence with the subjects requires a quasi-ethnographic approach that implies living with them for extended periods of time (in some cases for one year or more). Berry and Rofel highlight that it is out of this relationship that the 'social and political commentary of the film' is able to develop (Berry and Rofel 2010, 11). Duan Jinchuan, one of the pioneering figures of new style Chinese documentaries, similarly stressed the importance of building a relationship with the filmed subjects (Lü 2003, 96; see also Robinson 2010).

In light of this, Return to Phoenix Bridge, widely referred to as one of the earliest independent documentaries focussing on the everyday life of female migrant workers, managed to de-dramatise the depiction of these women. This was accomplished through the use of long sequences simply concentrating on these women's daily chores and living conditions. In Along the Railroad, a 2001 film 
focussing on the lives of vagrants living beside the railway tracks in Baoji, Shaanxi province, Du Haibin provided a platform for people who can hardly find space to voice their views on their own lives, or on society more broadly. Hence, to some extent, the film opened up a space for making visible the subjectivities of people located at the lowest rungs of society, the so-called 'blind migrants' (mangliu). By leaving ample time for the subjects' narration, making their everyday life visible along with the space they live in and their emotions and aspirations, the rather homogenising category of 'blind migrant' is somehow fissured. The long sequence shots exposed quite crudely the very harshness of their everyday living conditions, as well as their own reflections on the precariousness of their existence. As one of the characters in the film said: 'Nowhere to stay when it was cold, nothing to eat when hungry, no doctors to see when sick. It made me feel sad about my life.'
To some extent, such exposure stood at logger's head with the quite mainstreambut far from undisputed-idea that personal efforts inevitably lead to improvement in one's condition, a value which has become a major mode of legitimation of access to wealth and status in post-Mao China.

\section{An Embodied \\ Characterisation of the Rural Condition}

Through the subjects they portray, through their narratives, and through the bodies of their characters, the documentary films explored in this essay hint at powerful markers of the politico-historically produced rural-urban chasm and the traps of the political economy underpinning rapid economic growth in postMao China. The way these films mediate the rural conditions experienced by migrants is again, on the whole, quite different from that of the mainstream media narrative of the 1980s and 1990s, which linked material poverty to

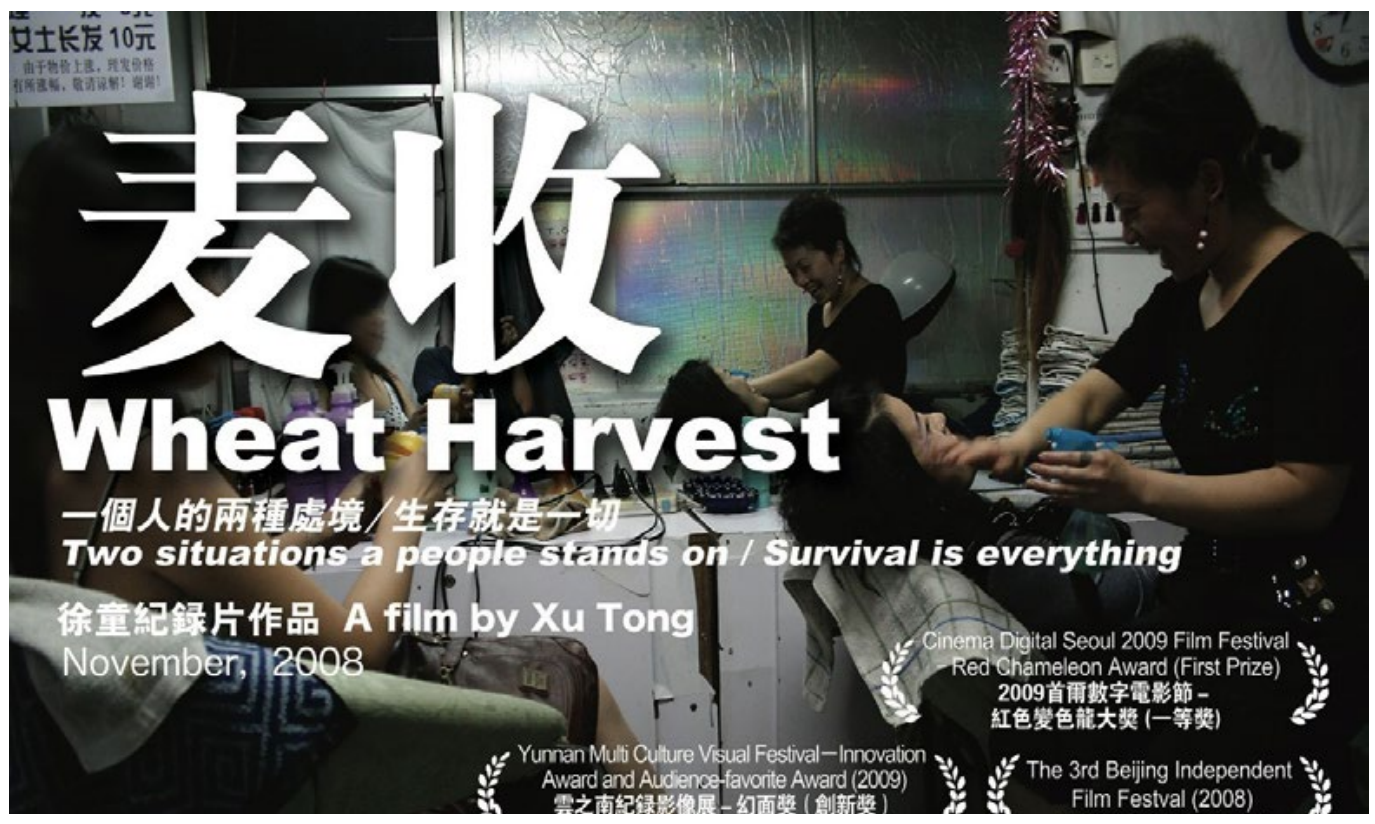




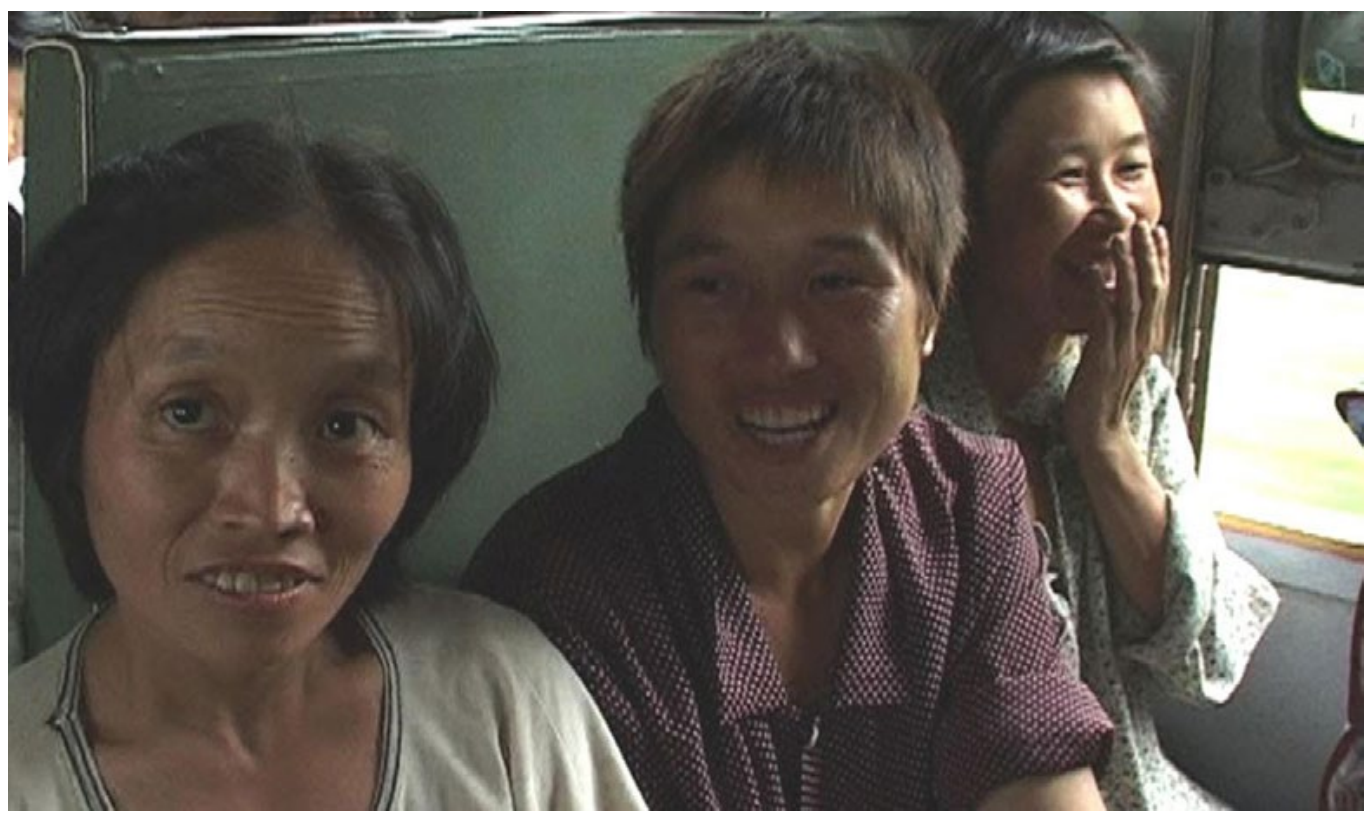

Still from Railroad of

Hope, Ying Ning (2002).

subjective or cultural poverty characterised by the 'low quality' (di suzhi) of the rural populace (Yan 2008; Sun 2013). They do so in an embodied manner, by enabling the expression of the rural condition as lived experience that often causes hardship and suffering.

In filmic representations, one sees a recurring background of poverty, disease, and material constraints, such as debts, unaffordable health or education costs, family normative pressures, and violence. In her latest book, Pun Ngai describes how in the 1980s and 1990s, policies related to agriculture, education, and health in the countryside combined with political economies in urban areas to produce labour markets that favoured massive and rapid capital accumulation. She also describes how these policies have enabled 'a production regime within which a separation exists between the production sphere in industrial regions and social reproduction in rural areas' (Pun 2016, 33-34). In a specific passage of Railroad of Hope, one of the first documentary films shot with a DV camera by filmmaker Ying Ning, this embodied hardship of the rural condition takes on a highly tragic and intense form in the tale of a woman who-in front of her child-explains that almost 20 years before she had been forced to marry a man she did not know, and that since then she had to live with this extraordinarily heavy load so as not to sadden her parents and to preserve her son's future:

The woman: 'Since 1982 I have lost any joy in life.'

The filming assistant: 'If you were to live again, what kind of life would you wish to have?

The woman: 'I have no wishes any more.' 
These Chinese documentary films also enable the viewers to get a glimpse of the multiplicity, complexity, and ambivalence of the motives that rural migrants put forward in order to explain their decisions to leave their hometowns: compelling rural poverty (debts, cost of health and education), the wish to become more independent from their family, the hope to discover the world out there, etc. Along with the vast scholarship on rural-to-urban migration in China, they show that human experiences can never be reduced to a simple monocausal narrative. Chinese independent documentary films also allow us to approach the simultaneously empowering and highly constrained dimension of migrants' agency, showing how it develops both against the background of historically and institutionally produced economic forces (Brettel and Hollifield 2007, 21).

Remote Mountain, a film shot in 1995 in an illegal mine shaft in the Qinlian mountains, Qinghai province, more than 3,000 metres above sea level, features a compelling explanation of why three young people filmed in the mine had decided to migrate to work in such a dangerous environment. $\mathrm{Hu}$ Jie filmed the bodies of these minors very closely, and because of the narrowness of the shaft, one hears their breath as they dig and excavate full baskets of coal. In one specific passage, one of the men carrying a heavy yoke, replies to the filmmaker's question as to why he is still working in the shaft despite being critically ill with pneumoconiosis:

What I think of this? This is in order to live. We are here in order to earn a living, to get married, rebuild the house, send our kids to school. This is in order to live.

Railroad of Hope (2002) offers another perspective on the agency of rural migrants. The film revolves around the question of why these migrants decided to leave their mountainous hometown in Sichuan province to work in cotton fields in remote Xinjiang. Much of the film tends to lend credence to the idea that, while they were not literally compelled to leave, a set of powerful forces at home and in the destination area have somehow pushed them to get out of their hometown. The film also mediates the agency and the capacity of rural migrants to reflect on their lives, as well as on the factors limiting their endeavours. Two segments of this movie demonstrate how powerful material forces shape people's decisions. In the first, a terribly disfigured young woman, injured while toiling in a factory, exemplifies not only the constraints of the countryside, but also the structural violence of labour regimes in post-Mao China. The strength of this scene lies in the invisible but compelling forces that make this young lady, whose face has been irremediably damaged and who received minimal financial compensation for the injury, once again leaves her hometown to labour in the cotton fields in Xinjiang.

In the second segment, two women in their forties reply to the question: 'Do you feel happy?'

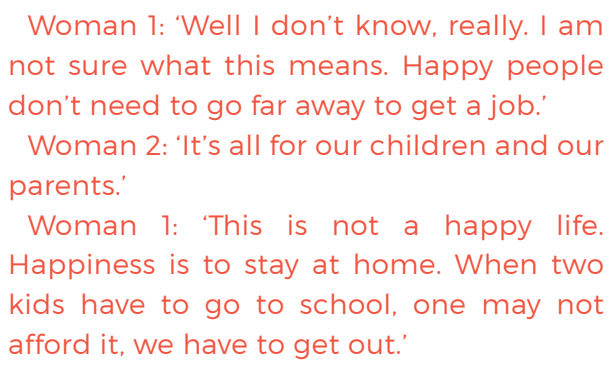

One should note that younger people in the same film tend to put forward reasons more related to positive and 'emancipatory values', such as the will to change one's condition compared to their older counterparts. What this shows is that the decisions these people make are interwoven and shaped by a number of forces, such as normative family and gender expectations, expectations regarding social mobility, material constraints related to health and education costs, as well as a politics of desire constructed within the migration 


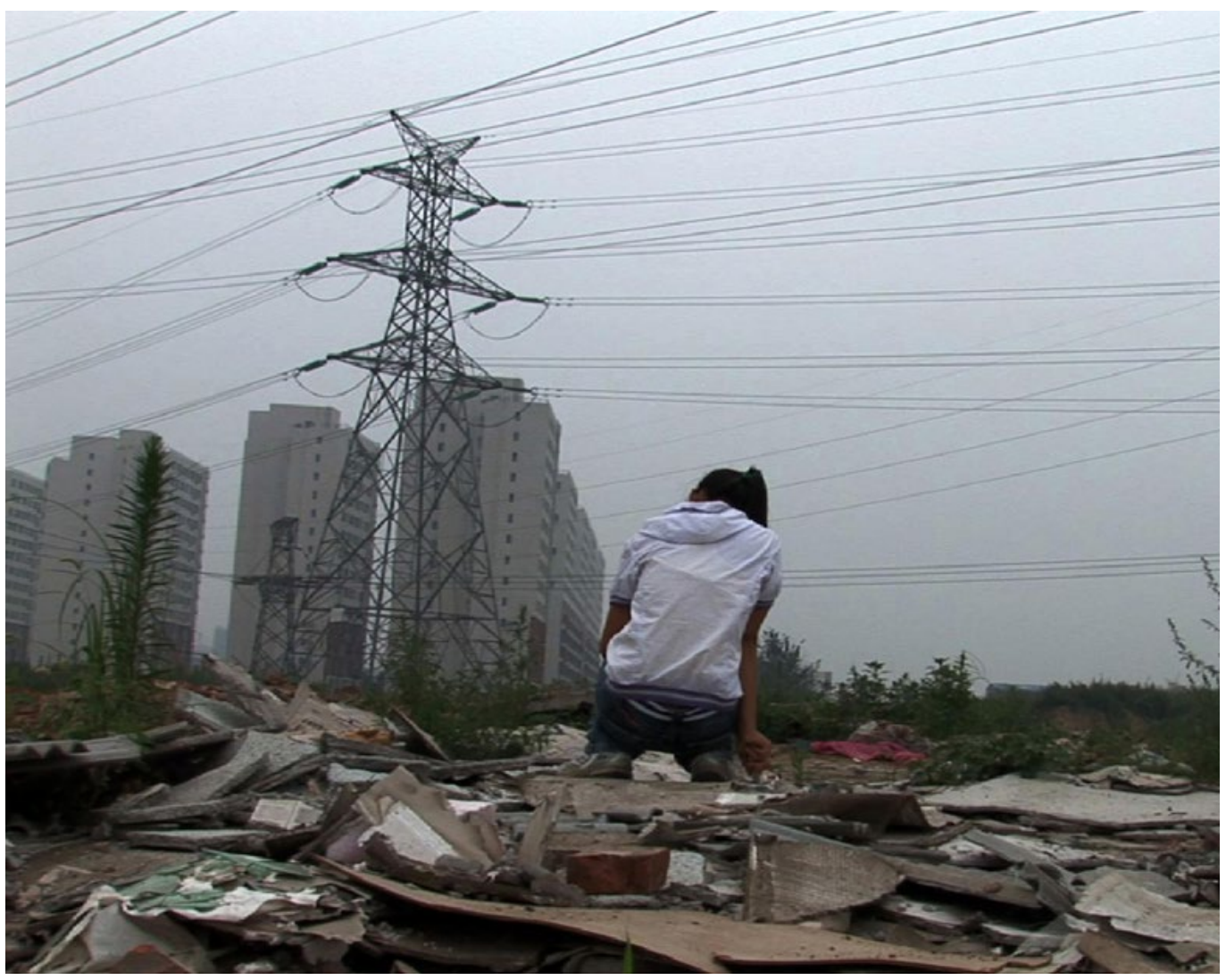

Still from When the

Bough Breaks, Ji Dan

(2010).

process. These elements all combine to shape migrant workers' subjectivities and agency in complex ways.

\section{When the Bough Breaks}

The movie which, I argue, manages to show most powerfully the complex ways in which rural migrants' aspirations and will engage with material forces-both at home and in the workplace-is When the Bough Breaks, a 2010 documentary by pioneer filmmaker Ji Dan (Litzinger 2016). The filmmaker spent a year with a family of scrap collectors she had met in 2004 while working on a film project on a Beijing school. Five years later, she heard that the eldest female sibling in the family had vanished-it is never quite clear in the movie whether she died, but she was supposedly forced into prostitution at some point. The film focusses on the relationship between the parents-in particular, the crippled father who lost one leg-and the two remaining daughters. $\mathrm{Xia}$, the eldest daughter, holds on to one single 
project with extraordinary determination: to enable her younger brother to attend a good high school and later university. Xia's perseverance and determination to succeed in her goal is contrasted by the father. He and his wife are originally at best ambivalent about their daughter's plan. He first agrees to it, recognising that 'education enables you to get anything', but later strongly opposes it, aware of what this dream would cost him and his family. At some point, Xia's mother, exhausted, tells her daughter: 'You know, it is already so tough right now, with this project of yours, the bough might break.' The father's entire body is so full of scars, exhaustion, hardship, and suffering. His body bespeaks precariousness, liminal subsistence, which leans towards physically and psychological collapse, alcoholism, and violence.

Through these characters of the father and daughter, in a single documentary Ji Dan manages to shed light on the complexity of what shapes the agency of rural migrants in today's China: a mix of powerful aspirations to improve one's condition and equally powerful forces that tend to maintain them in a subaltern position. Throughout the film, the daughter is ready to make any sacrificesuch as dropping out of school herself to earn money-so that her younger brother can enter a good high school. At one point, Xia says: 'I'll sell my blood to send him to school if I have to.' A series of implicit questions run through the film: what kind of political economy pushes people to endure such hardships and make such sacrifices? Would it not be wiser to listen to Xia's brother, who, perhaps tired of shouldering such normative pressure, at one point suggests that it might be better to simply let him attend an ordinary school? But by doing so, would this not prevent him from having any chance of accessing university? And would this not essentially be making a concession to some kind of social determinism according to which rural people ought to only perform the jobs for which they are suited? These are complex issues relating to the institutionally unfair nature of the education system, the structural obstacles to social mobility, and the enduring subaltern condition of rural migrants. Ji Dan manages to mediate this tension and complexity in an incredibly powerful way.

In conclusion, these Chinese documentaries allow us to approach core dimensions of the subaltern condition of migrant workers-of their determination, agency, and modes of engagements with the world. To a certain extent, these films provide subtle insights into the societal and socioeconomic transformations linked to unprecedented growth and massive capital accumulation that took place in China over the last three decades. They not only shed new light on the experiences of migrant workers by making their hopes, desires, and embodied hardships visible, but also illustrate how all this suffering constitutes an important, if not fundamental, part of such transformations. 
This text is taken from Dog Days: A Year of Chinese Labour, Civil Society, and Rights, Made in China Yearbook 2018, edited by Ivan Franceschini and Nicholas Loubere, published 2019 by ANU Press, The Australian National University, Canberra, Australia.

doi.org/10.22459/MIC.04.2019.47 